\title{
A televisão além de si mesma na América Latina ${ }^{1}$ \\ Television beyond itself in Latin America
}

\author{
G UILLERMO OROZC O ${ }^{\mathrm{a}}$ \\ Universidad de Guadalajara. Guadalajara - Jalisco, México \\ TOB Y MILLER \\ Universidad del Norte. Barranquilla - Atlántico, Colômbia
}

\section{RESUMO}

Na América Latina, a televisão continua sendo um meio de comunicação importante; a história, a política, o mercado e, principalmente, toda a cultura e audiência são o que a mantêm viva. Apesar de os jovens estarem migrando para outras telas, os conteúdos da televisão continuam sendo referência nas experiências audiovisuais de todos. Com as mudanças na recepção, na produção, na programação e nos modelos de negócio, a televisão, em vez de desaparecer, explode e se amplia no televisivo como experiência múltipla e oportunidade de reinvenção de suas audiências.

Palavras-chave: Televisão, realismo mágico, cultura, América Latina, audiência, mestiçagem

\begin{abstract}
Television in Latin America continues to be an important medium for the population; politics, history, the market, and especially the culture and its audiences keep television alive. In spite of the fact that millennials enjoy television from several screens, television contents remain as a reference in everybody's audiovisual experiences. With changes in its reception, production, programming, and business models, television booms, instead of disappearing, amplifying itself into the televisual medium, keeping itself as a multicultural experience, and as a unique opportunity for its audiences' reinvention of themselves.
\end{abstract}

Keywords: Television, miscegenation, magical realism, solitude, culture

\footnotetext{
${ }^{1}$ Versão do artigo publicado em Comunicación y Sociedad, Guadalajara, set.-dez. 2017. Disponível em: $<$ https://bit. ly/2G3Wp2k $>$. Acesso em: 6 dez. 2018. Tradução: Richard Romancini.

${ }^{a}$ Professor e pesquisador da Universidad de Guadalajara. Orcid: http://orcid.org/00000001-7943-2217. E-mail: guillermoorozcog@hotmail.com

${ }^{\mathrm{b}}$ Professor e pesquisador da Universidad del Norte. Orcid: http://orcid.org/0000-00024957-7770. E-mail: tobym69@icloud.com
} 
OMPREENDER A TELEVISÃO ou qualquer um dos meios de comunicação hoje pressupõe muito mais do que apenas explicar sua evolução tecnológica, comercial ou política, apesar do deslumbramento causado por invenções e dispositivos digitais, dos novos modelos de negócios e dos variados acordos, pactos e modalidades entre público e privado e entre global e local em todo o mundo (Maxwell; Miller, 2014; Miller, 2016). A explosão contemporânea da televisão, uma vez que diversificou, transformou e ampliou suas formas de existência, amplificou a própria ideia de televisão para algo diferente e sem precedentes, como fonte convergente do audiovisual ou do televisivo - tanto que, para muitos, parece desaparecer, razão pela qual tem havido discussões contraditórias e até esquizofrênicas sobre o fim da televisão (Buonanno, 2015; Scolari, 2016).

Além dessa discussão internacional, em que a televisão é vista como um meio em transição e prestes a desaparecer, neste texto partimos da conviç̧ão provocativa de que a televisão, como qualquer outro meio de comunicação, é muitas coisas ao mesmo tempo. E enfatizamos muitas coisas, porque a maioria dos discursos sobre a existência ameaçada da televisão sublinha quase exclusivamente sua dimensão midiática-tecnológica - que, claro, está sendo superada por telas inteligentes, o que se destaca nas preferências das audiências. A televisão é também uma fonte de entretenimento, informação, aculturação e disseminação de mensagens políticas, publicitárias e educativas.

Reconhecemos que a televisão está em transição, entrentanto, não em extinção, coexistindo com outras telas e reconvertendo-se em um meio transcendente e versátil, não apenas por suas propriedades intrínsecas como mídia e sua crescente convergência com muitos dispositivos, mas especialmente pelas características específicas das regiões e culturas nas quais foi inserida e se desenvolve. Portanto, nestas páginas propomos ver a TV além dela mesma, a partir de uma região específica, a América Latina, histórica, cultural e politicamente única; só a partir daí acreditamos revelar-se compreensível o vínculo multifacetado e o profundo significado da televisão para os latino-americanos. Um significado que não advém apenas a partir de sua tela, mas é construído e reconstruído diante dela, entre suas audiências em variadas interações com os conteúdos, o televisivo e sua própria história e cultura (Orozco, 2016). Para conseguir isso, propomos aqui uma perspectiva analítica incomum na literatura sobre a mídia, que incide sobre determinados elementos que não são sempre evidentes em si mesmos, mas ainda assim denotam sua existência se manifestando de várias maneiras sutis, não de modo direto e frontal, como muitos dos elementos mais profundos da cultura latino-americana. 


\section{A ANTIGA VERDADE DA REGIÃO LATINO-AMERICANA}

A América Latina é a região mais pós-colonial e menos pós-colonial do mundo. É a mais pós-colonial porque obteve essa condição antes da maior parte da Ásia e da África, e é a menos pós-colonial porque continua a ser dominada pelas duas línguas dos seus antigos colonizadores (espanhol e português), além de existir uma crescente e conflituosa interdependência com a outra América e a língua inglesa, invasivas, enquanto as várias línguas nativas, indígenas, típicas dos habitantes da região antes de sua conquista - muitas das quais em sério risco de extinção -, não são reconhecidas.

A noção de realismo mágico, amplamente relacionada à literatura e a arte latino-americanas, define e constitui grande parte da expressão de tradição e modernidade da região - e, como propomos aqui, permeia o intercâmbio entre a ficção televisiva e o público. O realismo mágico coincide com as ideologias oficiais e vernaculares do continente sobre a mestiçagem ou o mestiço como testemunho de uma história compartilhada de invasão, violência sexual e escravidão que remonta a centenas de anos. No entanto, a mestiçagem na América Latina não é, e nem poderia ser, uma descrição geral de um bem-sucedido multiculturalismo, inclusivo e popular, tampouco pretendemos que seja uma definição neutra.

Para o espanto de muitos, as audiências latino-americanas interagem ativamente com a televisão de massa e vertical, especialmente com seus conteúdos de ficção, produzindo criativamente novos entendimentos de seu próprio mundo e de si mesmas, inserindo nela novas histórias, ilusões e expectativas de um mundo melhor e, acima de tudo, seu, que compartilham com seus grupos sociais durante a audiência coletiva justamente a partir do final dos episódios das telenovelas.

Na região da América Latina, a televisão não necessariamente converge, mas se multiplica sincronicamente. É uma televisão que, com os avanços tecnológicos, se expande e se amplia, em vez de ser excluída, adquirindo novas formas, sem perder todas as anteriores. Como os personagens Pokémon - ou Pocket Monsters ("monstros de bolso") -, que têm um conjunto de atributos que colocam em ação em suas variadas interações entre si, mas há sempre um ou mais atributos originais que permanecem, fazendo com que mantenham seu caráter próprio (Orozco, 2016).

A respeito da convivência da televisão com os demais meios, García Canclini (2008: 390) defende que:

A fusão da multimídia está correlacionada às mudanças no consumo cultural. Portanto, abordagens macrossociológicas também precisam de perspectiva 
antropológica, mais qualitativa, para entender como os modos de acesso, os bens culturais e as formas de comunicação estão se reorganizando.

Entendemos, assim, que a inovação tecnológica normalmente deriva de relações sociais e formas culturais que condicionam a escolha, o investimento e o desenvolvimento dos meios de comunicação (Williams, 1989) - desse modo, a relação se torna recíproca. A mais recente reorganização envolve uma infinidade de formas; por isso, é difícil falar do fim da televisão, um meio que tem sido a maior indústria de entretenimento audiovisual e fonte de informação na região durante as últimas seis décadas.

Os latino-americanos assistem mais televisão do que nunca; por exemplo, o peruano médio passa nove horas por dia em frente a diferentes telas, desfrutando de uma variedade de formatos. No Brasil, são oito horas, e no México, sete (Millward Brown, 2014) - ou seja, um terço da vida de um cidadão. Naturalmente, o número de horas não é o único fator significativo. Em termos qualitativos, as audiências misturam várias opções de televisão: gêneros estabelecidos, como novelas e séries dramáticas; vídeos profissionais e amadores; esportes, principalmente futebol; e filmes, que podem ser industriais ou artesanais (Smith, 2014). A respeito da audiência contemporânea, é crucial entender a forma como as pessoas olham para as telas em um continuum e como prática social, além da televisão (Orozco, 1996). De acordo com as propostas de Benamou (2009: 152):

O melodrama televisivo (o mundo das telenovelas, nesse caso) não é apenas um lugar no qual as tensões entre o nacional, o local e o global se articulam e se manifestam: é também uma ponte comunicativa que une os espectadores através das esferas nacionais, regionais ampliadas e globais de transmissão e recepção, trabalhando para moldar novas comunidades culturais e interculturais.

A televidência - o processo de assistir televisão -, prática cotidiana de interação com a telinha, tem várias implicações na vida cotidiana em termos de atividade e emoção, e é o palco do histórico enlace entre a televisão e suas audiências (Orozco, 2014b). Elas retiram da televisão uma variedade de mensagens e normas sobre os papéis paternos e pedagógicos, afetando tudo, desde a organização da vida doméstica até o comportamento na escola e na vida cotidiana. Como aquelas mães quase analfabetas que aconselham suas filhas a "assistir TV" para que aprendam a se comportar na sociedade e, principalmente, lidar com os namorados (Orozco, 2001). A televidência também estabelece cumplicidade entre 
A oralidade, que perdura como experiência cultural primária das maiorias, e a visualidade tecnológica, essa forma de "oralidade secundária", que tecem e organizam as gramáticas tecnoperceptivas do rádio, do cinema, do vídeo e da televisão (comunicação oral que domina o cotidiano, como parte do crescimento, e comunicação oral secundária, que deriva de ouvir e assistir o rádio, o cinema, o vídeo e a televisão). (Martín-Barbero; Rey, 1999: 34)

$\mathrm{Na}$ América Latina, como em muitos outros lugares, as distinções entre o uso de uma variedade de telas e tipos de serviço não são completas nem se realizam rapidamente. Pelo contrário, há um fluxo através das categorias, com diferenças estabelecidas como práticas sociais em vez de essências tecnológicas (Verón, 2009). Os dados mais recentes também confirmam que os latino-americanos assistem televisão majoritariamente com outras pessoas, em parte devido à necessidade de compartilhar recursos em uma área onde a riqueza tem distribuição bastante desigual (Ceron, 2015), mas também porque é nesse âmbito, na troca entre audiências, que o sentido do que é visto na tela é construído. Dos mais de 600 milhões de cidadãos na América Latina, aproximadamente metade se conectou à internet (Miniwatts Marketing Group, 2016; 2017). O México, o maior e mais influente país de língua espanhola, tem 70 milhões de usuários, o que significa 63\% da população mexicana (Asociación de Internet.mx, 2017).

A Comissão Econômica para a América Latina e o Caribe (Rojas; Poveda, 2015) indica que a proporção de latino-americanos com acesso regular a banda larga mais do que dobrou entre 2006 e 2013, indo de 20,7\% para 46,7\%. Mas esses números podem ser enganosos: estar on-line em algum momento da vida ou em determinado ano é completamente diferente de desfrutar da banda larga diariamente, e há variação dramática entre os países da região. Ademais, isso mal se compara com a média de $79 \%$ da Organização para Cooperação e Desenvolvimento Econômico (OCDE). Por outro lado, a qualidade da banda larga na América Latina, em contraste com, por exemplo, a da Suécia e do Japão, é ruim, o que diminui a capacidade de os cidadãos baixarem e transmitirem em alta largura de banda.

Isso tem implicações óbvias para a não substituição da televisão como sistema de distribuição de informação (Organización para la Cooperación y el Desarrollo Económicos, 2012). E, embora o uso de smartphones tenha disparado nos últimos cinco anos, apenas uma minoria está conectada à banda larga de alta qualidade - seja via 3G, seja, ainda menos, 5G (Millward Brown, 2014; Qualcomm..., 2015). Também há fortes disparidades de preços na região. Um megabit por segundo no México custa nove dólares, ou $1 \%$ da renda média mensal; na Bolívia, custa 63, ou 31\%, respectivamente. O acesso, por sua vez, 
é estruturado de forma desigual em termos de raça, ocupação e região; os indígenas representam um terço dos trabalhadores rurais na América Latina, e mais da metade em alguns países, mas estão essencialmente desconectados. A brecha digital entre os povos indígenas e o resto da população no México é de 0,3, no Panamá, de 0,7 e, na Venezuela, de 0,6 (Bianchi, 2015).

Daí a complexidade e, ao mesmo tempo, o potencial, devido às grandes e antagônicas diferenças, contidos numa noção como a de mestiçagem para explicar a televisão. Noção que ao mesmo tempo ilumina e obscurece a maneira como, por exemplo, as ideias de mistura racial e cultural podem ser vistas como sinais de orgulho, mas a desigualdade contida nelas perdura até hoje, graças, precisamente, à diferença racial e cultural. Essa extraordinária ironia da mestiçagem é capturada no cotidiano das maiorias na região latino-americana, no qual a televisão está fortemente presente.

Diferentemente dos telefones, tablets e laptops, as grandes telas - a maioria Smart TV screens - geralmente têm locais definidos nos lares, mas não como os aparelhos de TV do passado, semelhantes aos móveis. As novas telas nos países da América Latina tendem a estar nas paredes, não como obras de arte, mas localizadas de modo a facilitar a visão conjunta da família - ou seja, para favorecer uma experiência de televidência coletiva. Além da esfera doméstica, os grandes televisores são proeminentes no espaço público, como em shoppings centers, bares, restaurantes, estações de metrô das principais cidades e até mesmo mercados (Repoll, 2014).

Os latino-americanos que podem adquirir uma tela combinam a compra do mais novo aparelho com o mundial de futebol, a cada quatro anos (Melgar, 2012). Eles demonstram grande paixão por assistir esse e outros esportes em telas grandes, em bares e outros locais coletivos, assim como o clássico bar esportivo estadunidense (García, 2010; McCarthy, 1995; Wenner, 1998).

A opção de sair para aproveitar um jogo de futebol ou beisebol em uma tela grande evoca o mesmo empenho e prazer de estar no cinema para assistir um filme e, na região, é um modo dominante de consumir esportes na tela. Com exceção da Argentina, onde $80 \%$ da população tem televisão por assinatura, a maioria dos outros países não tem acesso a esse tipo de recepção na esfera doméstica (Ceron, 2015). No próprio México, a televisão paga foi, por alguns

${ }^{2}$ A Argentina também se diferencia pelo fato de que, durante grande parte da dinastia política dos Kirchner, de 2000 a 2015, o Estado assumiu a responsabilidade de televisionar e transmitir o futebol por sinal gratuito de TV (Mariotto, 2015). anos, um privilégio de pouco mais de um terço da população. Em 2016 o número de telespectadores de algum sistema de televisão paga era de apenas 55\% (Observatório Iberoamericano de la Ficción Televisiva, 2016)2.

Esses contextos de visualização não substituem a maneira clássica de assistir televisão em casa, mas são novos suplementos que misturam entretenimento, socialização e prazeres. A televisão, em geral, seja em contextos domésticos ou 
públicos, é principalmente uma fonte de entretenimento mental e sensorial emocionalmente ativo (Daswani, 2015; Observatório Iberoamericano de la Ficción Televisiva, 2015).

\section{A REINVENÇÃO DA TELEVISÃO LATINO-AMERICANA}

A televisão na América Latina não é determinada apenas pelas tecnologias, como já discutimos, nem pelos horários e tipos de programação, mas pelos gostos e interpretações das audiências, para quem o texto da tela se torna um pretexto para a comunicação e convivência. A vida cotidiana torna-se uma mistura efervescente com as novelas, assim como com o realismo mágico, tornando os programas e as experiências de vida uma combinação do ficcional e do factual, com linhas demarcatórias indefinidas. Assistir televisão, desse modo, torna-se um lugar seguro para muitos latino-americanos para se emocionar, chorar e rir com prazer, sem consequências sociais, e refletir sobre a desigualdade que tanto desvanece a suposta união da mestiçagem (Orozco, 2001). O autor colombiano do realismo mágico e ganhador do Prêmio Nobel, Gabriel García Márquez (2002), intitulou suas memórias Vivir para contarla. A vida na América Latina é vista em grande parte como uma narrativa a ser recontada e reinventada toda vez que há uma oportunidade de fazê-lo, usando os temas e histórias de ficção para organizar, reorganizar e enriquecer a vida diante do sofrimento extraordinário, da injustiça e da desigualdade das maiorias. Esse realismo mágico (imaginado, amado, inventado) é um contraste gritante com o empirismo britânico ou o pragmatismo estadunidense, que assume a firme certeza de que a verdade pode ser conhecida de maneira não enfeitada pela ficção. A diferença cultural é, no fundo, um meio de representar tanto a profunda mistura de cultura e linguagem, mas também a maneira pela qual a dor e a exploração são experimentadas de maneira tão desigual.

A partir da revolucionária radionovela cubana e sua expansão em toda a América Latina, as telenovelas se tornaram oportunidades de inventar histórias, imaginar vidas, buscar a libertação, punir os maus, participar das reinterpretações, encorajar os encontros pessoais e buscar novas formas de comunicação.

Sem saber e sem procurar deixar um registro televisivo ou audiovisual, o público latino-americano vem criando extensões transmídia constantemente. Essa simbiose entre audiências e telenovelas perdura além do momento de olhar para a tela; ganha expressão na vida privada e pública, com os familiares, os vizinhos e os colegas de trabalho (Martín-Barbero et al., 1992). O que acontece na televisão é transformado em propriedade, se não legal, cultural das audiências, pois elas processam informações, as relacionam com suas próprias vidas e dão novo significado ao que é visto (Orozco, 2014a). 
A ficção televisiva é o gênero que mais atrai investimento financeiro e público. Esse investimento não se dá apenas por meio dos custos de produção e publicidade. Ele também assume a forma de colocação de produtos e propaganda política e comercial dentro das histórias (Orozco; Franco, 2011). A Venezuela sob Chávez e o México sob o Partido Revolucionario Institucional (PRI) são exemplos de tais investimentos. No México, as despesas de propaganda na ficção, que poderíamos chamar de merchandising político, ultrapassaram 205 milhões de dólares em 2012, muito mais do que partidos políticos gastaram em publicidade formal de campanha (Fundar Centro de Análisis e Investigación, 2015).

Como em outras regiões, a televisão na América Latina está diversificando seus produtos e formas de acesso, produzindo programas disponibilizados por meio de smartphones e criando o novo gênero das webnovelas, muito curtas, que preservam a intensidade emocional de suas progenitoras, mas adaptando o formato para as circunstâncias atuais, os dispositivos e as expectativas do público. Para as classes populares, contudo, o modelo antigo ainda é o mais importante (Orozco et al., 2012).

A combinação de publicidade e propaganda em programas de ficção é uma resposta ao fascínio dos cidadãos-audiência com o gênero e a indústria da ficção, como relatado em estudos acadêmicos sobre o impacto das telenovelas sobre eles (Clifford, 2005; Igartua; Vega, 2014; Slade; Beckenham, 2005).

Yo soy Betty, la fea, uma telenovela colombiana refilmada, graças à venda do formato, nos Estados Unidos, como Ugly Betty, e no México, como La fea más bella, exemplifica essas tendências. Uma semana antes das eleições presidenciais mexicanas de 2006, La fea más bella mostrou o seguinte diálogo: "Em quem você vai votar? Eu vou votar em Felipe Calderón”. Fora da tela, Calderón ganhou a eleição subsequente (Orozco; Franco, 2011). Esse exemplo histórico destaca a primazia da oralidade (comparada às formas visuais), mesmo dentro da própria novela, e o realismo mágico como uma mistura que tanto as audiências quanto a emissora de televisão podem produzir.

É claro que essa anedota não indica a aceitação geral de uma instrução, e não é assim que as inserções de produto (merchandising) funcionam. Na verdade, trata-se de construir um clima de normalidade, seja na compra de um determinado item ou numa escolha eleitoral específica.

\section{AS SOLIDÕES DA AMÉRICA LATINA}

A mestiçagem e o realismo mágico se entrelaçam com a solidão, ideia e conceito que aqui tomamos de dois dos títulos mais famosos do cânone da literatura latino-americana: O labirinto da solidão, do mexicano Octavio Paz 
(1950), premiado com o Nobel de Literatura, que reconheceu e incorporou um sentido trágico desse "desejo insatisfeito" que tem perseguido os cidadãos em toda a América Latina; e Cem anos de solidão, romance com o qual Gabriel García Márquez alcançou a fama, no final dos anos 1960, e que colocou em circulação o realismo mágico em todo o mundo como forma de narrar e viver. A esse respeito, Martin-Barbero (2002) elaborou a metáfora do século da solidão para sugerir que, desde a independência da América Latina na segunda década do século XIX, houve "dois cem" anos de solidão, não uma centena. Essas solidões também encontram explicação na comunicação insuficiente e deficiente entre os países latino-americanos e seus diferentes grupos sociais, levando a uma história de violência externa e interna. Os duzentos anos de solidão foram caracterizados por massacre após massacre, ditadura após ditadura. A região tem sido afetada por regimes incompetentes e autoritários em diferentes momentos, em Cuba, no Haiti, na República Dominicana, na Nicarágua, em Honduras, na Guatemala, em El Salvador, na Bolívia, no Uruguai, no Chile, na Argentina, no Brasil, no Equador e no Paraguai. No século passado, a Operação Condor do Chile e o massacre de Tlatelolco do México corroeram as perspectivas e as esperanças dos latino-americanos, especialmente dos jovens, em toda a região.

O Movimento Zapatista, surgido em $1^{\circ}$ de janeiro de 1994, no México, coincidindo com a criação do primeiro Acordo de Livre Comércio entre este, os Estados Unidos e o Canadá, poderia ter sido outra América; foi anunciado, mas logo sucumbiu. E embora os zapatistas tenham surpreendido o país, o continente e depois o mundo, esbanjando a sabedoria indígena acumulada ao longo desses duzentos anos de solidão e isolamento e tornando-a pela primeira vez conhecida além de seu território original, isso se deu a partir da internet e da imprensa escrita de vanguarda, não da televisão. O governo mexicano proibiu a televisão do país de dar aos zapatistas câmera ou microfone, por meio de uma ordem escrita pelo Ministério do Interior (Orozco, 1994).

\section{A FICÇÃO QUE PRETENDE SER REALIDADE E A REALIDADE QUE SE TORNA APENAS FICÇÃO}

No meio da solidão vem o sonho de prosperidade coletiva. A ficção torna-se, então, estímulo para sonhar com um mundo diferente, no qual o não real pode tornar-se real à vontade (Orozco, 2014a). É uma saída possível do labirinto, através da catarse, chorando com a heroína em uma novela sem se sentir tolo ou culpado, identificando-se com o criminoso de uma série policial sem medo de prisão e encarceramento, ou gritando de prazer quando o jogador 
${ }^{3} \mathrm{Cf}$. dados sobre o longa em $<$ https://imdb.to/1oUaRWx $>$. Acesso em: 10 dez. 2018. de futebol favorito marca, apesar da incapacidade do telespectador de, por si mesmo, realmente chutar a bola para o gol.

A ficção televisiva e o esporte incorporam e estimulam uma abundância de sonhos, desejos e identificações na interseção entre a realidade e a tela. MartínBarbero e Rey (1999: 29) argumentam que, "se a televisão atrai, é porque a rua expulsa; é dos medos que vivem os meios". Eles habilmente questionam a maneira pela qual os monopolistas da mídia atendem os gostos textuais de seus públicos, satisfazendo as necessidades culturais inatas dos latino-americanos. Isso é o que os economistas neoclássicos chamariam de "racionalidade limitada" (Simon, 1979), bem longe de oferecer o que realmente se deseja - nesse caso, uma saída segura do labirinto.

Mas Martín-Barbero e Rey (1999) também argumentam que a televisão teve influência positiva como ator decisivo na mudança política na América Latina, oferecendo novas formas de fazer política. A campanha do No, de 1988, no Chile é um exemplo. Quando surgiu a oportunidade de rejeitar o ditador Augusto Pinochet - que buscava legitimidade popular por meio de um plebiscito para combater a condenação global de seus sistemáticos abusos dos direitos humanos, como prisões em massa, tortura e assassinato -, a campanha publicitária de esquerda venceu. A nação estava dividida meio a meio quando a campanha começou, terminando com o triunfo da oposição, com base, em grande parte, em seu material promocional de televisão (Khazan, 2013; National Democratic Institute for International Affairs, 1988).

A eleição foi uma vitória da democracia, da alegria, da autoexpressão; Pablo Larraín, cineasta chileno, imortalizou o triunfo em seu filme No (2012), estrelado pelo ator mexicano Gael García Bernal, que enfatiza o papel da comunicação e da televisão ${ }^{3}$.

Algo semelhante aconteceu no México durante a década de 1970, a partir de várias novelas produzidas pelo ex-diretor teatral e executivo de televisão Miguel Sabido, transmitidas pela Televisa. Elas foram pensadas como novelas com mensagens ou "novelas de reforço social" (Cueva et al., 2011). As questões abordadas incluíam, entre outras, o controle de natalidade e a alfabetização. $\mathrm{O}$ caso mostrou que, dos dez milhões de mexicanos adultos analfabetos da época, um milhão logo se matriculou em aulas de alfabetização promovidas pelo Ministério da Educação Pública após assistir à telenovela Ven Conmigo (1975). E depois de Acompáñame (1977), 562.464 pessoas estavam usando contraceptivos, quase um terço a mais do que antes de sua transmissão (Garnica, 2011).

Nos últimos cinco anos, na maioria dos países latino-americanos, o horário nobre foi dominado por novelas produzidas regionalmente (Vassallo; Orozco, 2014). O Brasil, o México, a Colômbia e a Argentina são os principais produtores, 
embora o Uruguai, o Equador e o Chile também tenham ingressado no mercado (Observatorio Iberoamericano de la Ficción Televisiva, 2014). O Observatório Ibero-Americano de Ficção Televisiva (Obitel) mostrou que a ficção nacional de televisão, em cada região, obtém caracteristicamente os maiores índices em toda a América Latina. Isso foi teorizado como resultado das preferências do público pela proximidade cultural, quando ela está disponível (Sinclair; Straubhaar, 2013).

O sucesso de tal proximidade não necessariamente vai contra o constante poder dos Estados Unidos como exportador de conteúdo de televisão para a região, devido à sua capacidade de fixar preços abaixo dos custos do material local, usar altos valores de produção e se direcionar a canais especializados de cabo e satélite (Miller, 2010).

\section{TELEVISÃO QUE PERDURA COMO PARTE ESSENCIAL DO REINO DO TELEVISIVO}

Claro, estamos em uma nova era. A televisão, o cinema, o rádio e a imprensa continuam a ter papéis importantes, mesmo quando lutam pela coexistência e contra a dominação de novas telas, novas tecnologias e, sobretudo, novas "figuras da razão" da comunicação (Martin-Barbero, 2001). Essa nova era foi rotulada de pós-televisão, mas autores como Buonanno (2015) discordam, reconhecendo que a televisão deve entrar em uma nova constelação de comunicações, isto é - diríamos nós -, no cenário midiático e televisivo contemporâneo (Press; Williams, 2010).

Numa análise comparativa de dois pontos de vista centrais sobre o fim da televisão, o eurocêntrico e o latino-americano, o pesquisador argentino Carlón (2012) conclui que, ao passo que a postura eurocêntrica enfatiza o fim da televisão, a visão latino-americana destaca a possibilidade de uma vida mais longa para esse meio, apesar de sua produção, distribuição e consumo estarem mudando. A hegemonia anterior da televisão como máquina cultural da vida cotidiana pode agora estar enfrentando a concorrência de outros dispositivos, mas continua sendo central programadora da vida social.

Enquanto os autores que representam a abordagem anglo-saxônica, como Katz (2009) - cf. também Carey (2005), Carlón; Scolari (2014), Friedman (2013), Piscitelli (2010) -, enfatizam os avanços tecnológicos como as principais causas das mudanças na televisão, os autores latino-americanos prestam mais atenção às práticas sociais que favorecem as audiências do meio (Orozco, 2014c; Orozco; Miller, 2016). Pensamos que, além da base político-econômica, o sucesso da televisão reside na sua ontologia essencialista: as pessoas acreditam na evidência apresentada na tela. Nela vislumbram a realidade falada e vista, 


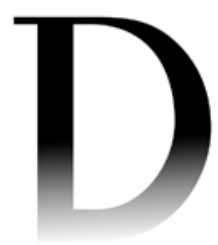

${ }^{4}$ Esse conceito foi proposto pela primeira vez por Orozco (2001) e revivido por Livingstone (2015).

aliada, paradoxalmente, ao mundo de fantasia da televisão e sua abertura à autoinserção dos espectadores (Orozco, 2014c). A noção classicamente denotativa, aparentemente não interpretativa, da realidade da televisão continua sendo válida (Hall et al., 1980; Scolari, 2013).

Essa experiência atingiu o ponto mais alto nas últimas duas décadas, tanto na América Latina quanto na Europa Ocidental e nos Estados Unidos. Por isso, as populações têm sido sujeitas à "audienciação" (convertendo-se em audiências) de modos que alteram o resto da vida cotidiana (Orozco, 1996). Ser uma audiência significa conectar-se com os outros e com o outro de forma mediada por telas, o que faz com que o conhecido não seja o objeto em si, mas sua representação na tela.

Essas formas de conhecimento agora também se misturam e perduram como "autocomunicação de massa" (Castells, 2009). O que antes era uma forma centralizada de comunicação ainda é importante, mas pode ser personalizado para experiências mais individuais. Essa nova tendência faz com que novas maneiras de experimentar a televisão coexistam com formas antigas da relação meios massivos-audiência. Sua textualidade e ressonância cultural nas Américas, pensamos, será decidida em grande parte pelo realismo mágico, mestiçagem e solidão de suas audiências, como tem sido historicamente. M

\section{REFERÊNCIAS}

ASOCIACIÓN DE INTERNET.MX. $13^{\circ}$ estudio sobre los hábitos de los usuarios de internet en México 2017. Cidade do México, 2017. Disponível em: $<$ https://bit.ly/2tg9yhl>. Acesso em: 23 nov. 2018.

BENAMOU, C. L. Televisual melodrama in an era of transnational migration: exporting the folkloric nation, harvesting the melancholic-sublime. In: SADLIER, D. J. (Ed.). Passion, pathos and entertainment: Latin American melodrama. Chicago: University of Illinois Press, 2009. p. 139-171.

BIANCHI, M. Digital age inequality in Latin America. Democracia Abierta, [S.l.], 24 jun. 2015. Disponível em: <https://bit.ly/2zmWl84>. Acesso em: 23 nov. 2018.

BUONANNO, M. Uma eulogia (prematura) do broadcast: o sentido do fim da televisão. MATRIZes, São Paulo, v. 9, n. 1, p. 67-86, 2015. DOI: http:// dx.doi.org/10.11606/issn.1982-8160.v9ilp67-86

CAREY, J. W. Historical pragmatism and the internet. New Media \& Society, Thousand Oaks, v. 7, n. 4, p. 443-455, 2005. DOI: https://doi. org/10.1177/1461444805054107 
CARLÓN, M. El fin de la televisión: una reflexión sobre los debates anglosajón y latinoamericano sobre el fin de la TV. In: OROZCO, G. (Coord.). TVmorfosis: la televisión abierta hacia la sociedad de redes. Cidade do México: Tintable, 2012. v. 1. p. 41-60. (Colección Tendencias).

CARLÓN, M.; SCOLARI, C. El fin de los medios masivos: el debate continúa. Buenos Aires: La Crujía, 2014.

CASTELLS, M. Comunicación y poder. Barcelona: Alianza, 2009.

CLIFFORD, R. Engaging the audience: the social imaginary of the novela. Television \& New Media, Thousand Oaks, v. 6, n. 4, p. 360-369, 2005. DOI: https://doi.org/10.1177/1527476405279859

CERON, R. ComScore IMS mobile in LatAm research study. ComScore, Reston, 20 abr. 2015. Disponível em: <https://bit.ly/2SFza02>. Acesso em: 23 nov. 2018.

CUEVA, A. et al. (Eds.). Telenovelas en México: nuestras íntimas extrañas. Cidade do México: Delphi, 2011.

DASWANI, M. Fitch visualiza panorama estable para el sector de medios latinoamericano. TVLatina.tv, Nova Iorque, 9 dez. 2015. Disponível em: $<$ https://bit.ly/2BpV0gN>. Acesso em: 23 nov. 2018.

FRIEDMAN, W. Worldwide pay TV on the rise, big growth in Asia. MediaPost, Nova Iorque, 23 maio 2013. Disponível em: <https://bit.ly/2KtkONp>. Acesso em: 23 nov. 2018.

FUNDAR CENTRO DE ANÁLISIS E INVESTIGACIÓN. Libertad de expresión en venta: acceso a información y censura indirecta en publicidad oficial. Cidade do México, 2015.

GARCÍA, H. La recepción televisiva en lugares públicos, fútbol televisivo y mediaciones: cambios en las prácticas sociales y cultura futbolera. 2010. Maestria en Comunicación - Universidad de Guadalajara, Guadalajara, 2010.

GARCÍA CANCLINI, N. Interview for the 9th Spanish Sociology Conference, 2007. Social Identities, Abingdon, v. 14, n. 3, p. 389-394, 2008. DOI: http:// dx.doi.org/10.1080/13504630802102770

GARCÍA MÁRQUEZ, G. Vivir para contarla. México: Random House Mondadori, 2002.

GARNICA, A. Las televisiones de un visionario: cómo Miguel Sabido contribuyó a la telenovela mexicana y al entretenimiento educativo. In: CUEVA, A. et al. (Eds.). Telenovelas en México: nuestras íntimas extrañas. Cidade do México: Delphi, 2011. p. 94-120.

HALL, S. et al. (eds.). Culture, media, language. Londres: Hutchinson, 1980.

IGARTUA, J.; VEGA, J. Processes and mechanisms of narrative persuasion in entertainment-education interventions through audiovisual fiction: the role 
of identification with characters. In: INTERNATIONAL CONFERENCE ON TECHNOLOGICAL ECOSYSTEMS FOR ENHANCING MULTICUlTURALITY, 2., 2014 Salamanca. Proceedings... Nova Iorque: Association for Computing Machinery, 2014. p. 311-316.

KATZ, E. The end of television? Annals of the American Academy of Political and Social Science, Thousand Oaks, v. 625, n. 1, p. 6-18, 2009. DOI: https:// doi.org/10.1177/0002716209337796

KHAZAN, O. 4 things the movie "NO" left out about real-life Chile. The Atlantic, Washington, DC, 29 mar. 2013. Disponível em: <https://bit.ly/2C2QYfK>. Acesso em: 23 nov. 2018.

LIVINGSTONE, S. Active audiences? The debate progresses but it is far from resolved. Communication Theory, Oxford, v. 25, n. 4, p. 439-446, 2015. DOI: http://dx.doi.org/10.1111/comt.12078

MARIOTTO, G. Consideraciones para la viabilidad de modificación de las leyes de medios en América Latina. In: OROZCO, G. (Coord.). TVmorfosis: television everywhere. Cidade do México: Tintable, 2015. v. 4. (Colección Tendencias).

MARTÍN-BARBERO, J. Al sur de la modernidad: comunicación, globalización y multiculturalidad. Pittsburgh: Instituto Internacional de Literatura Iberoamericana, 2001.

Oficio de cartógrafo: travesías latinoamericanas de la comunicación en la cultura. Santiago: Fondo de Cultura Económica, 2002.

MARTÍN-BARBERO, J. et al. (Eds.). Televisión y melodrama: géneros y lecturas de la telenovela en Colombia. Bogotá: Tercer Mundo, 1992.

MARTÍN-BARBERO, J.; REY, G. Los ejercicios del ver: hegemonía audiovisual y ficción televisiva. Barcelona: Gedisa, 1999.

MAXWELL, R.; MILLER, T. The hype of high-tech predictions for 2014. Psychology Today, Nova Iorque, 9 jan. 2014. Disponível em: $<$ https://bit. ly/2PPm0Ar>. Acesso em: 23 nov. 2018.

MCCARTHY, A. “The front row is reserved for scotch drinkers": early television's tavern audiences. Cinema Journal, Austin, v. 34, n. 4, p. 31-49, 1995. DOI: http://dx.doi.org/10.2307/1225576

MELGAR, L. México, mercado clave para venta de pantallas Samsung. El Economista, Cidade do México, 15 out. 2012. Disponível em: <https://bit. ly/2r0sZI3>. Acesso em: 23 nov. 2018.

MILLER, T. Television studies: the basics. Londres: Routledge, 2010. - ¿Creatividad en la era digital? ¿Digitalidad en la era creativa? In: OROZCO, G. (Coord.). TVmorfosis: la creatividad en la era digital. Cidade do México: Tintable, 2016. v. 5. (Colección Tendencias). 
MILLWARD BROWN. AdReaction: marketing in a multiscreen world. Londres, 2014. Disponível em: <https://bit.ly/1HO3TOQ >. Acesso em: 23 nov. 2018.

MINIWATTS MARKETING GROUP. Latin American internet usage statistics. Internet World Stats, Bhopal, 2016. Disponível em: <https://bit.ly/2QiDzIu $>$. Acesso em: 23 nov. 2018.

. World internet usage and population statistics. Internet World Stats, Bhopal, 2017. Disponível em: <https://bit.ly/JNZ65e >. Acesso em: 23 nov. 2018.

NATIONAL DEMOCRATIC INSTITUTE FOR INTERNATIONAL AFFAIRS. Chile's transition to democracy: the 1988 presidential plebiscite. Washington, DC, 1988.

OBSERVATORIO IBEROAMERICANO DE LA FICCIÓN TELEVISIVA. Transmedia production strategies in television fiction. Porto Alegre: Globo Universidade, 2014. Relaciones de género en la ficción televisiva. Porto Alegre: Globo Universidade, 2015.

. Reinvención de géneros y formatos de la ficción televisiva. Porto Alegre: Globo Universidade, 2016.

- Uma década de ficção televisiva na ibero-america: análise de 10 anos do Obitel. Rio de Janeiro: Globo Universidade, 2017.

ORGANIZACIÓN PARA LA COOPERACIÓN Y EL DESARROLLO ECONÓMICOS (OCDE). Perspectivas económicas de América Latina 2012: transformación del estado para el desarrollo. Santiago, 2012. Disponível em: <https://bit.ly/2Kzi29r>. Acesso em: 23 nov. 2018.

OROZCO, G. Chiapas, la otra guerra, sus protagonistas y la teleaudiencia. APUMA, n. 8, Madri, 1994.

. Televisión y audiencias: un enfoque cualitativo. Madri: Ediciones de la Torre, 1996.

. Televisión, audiencias y educación. Buenos Aires: Norma, 2001.

. Mexican research on TV: a tradition framed by a powerful quasi-monopolistic TV system. In: ALVARADO, M.; BUONANNO, M.; MILLER, T. (Eds.). The Sage handbook of television studies. Thousand Oaks: Sage, 2014a. p. 105-114.

Televidencias: comunicación, educación y ciudadanía. Guadalajara: Universidad de Guadalajara, 2014b.

. La televisión, lo televisivo y sus audiencias: el estallido con sus vínculos con la ficción. Telos, Madri, n. 99, p. 13-22, 2014c. Disponível em: <https:// bit.ly/2Pw8VXC>. Acesso em: 23 nov. 2018. 
Los públicos del nuevo espacio comunicativo. In: FRANCÉS, M.; OROZCO, G. (Coords.). Nuevos modelos mediáticos: diversidad usuarios y ventanas. Madri: Síntesis, 2016. p. 13-18.

OROZCO, G. et al. México: ficción a la carta: la programación a ritmo de la política. In: OROZCO, G.; VASSALLO, I. (Coords.). Anuario Obitel 2012: transnacionalización de la ficción televisiva en los países iberoamericanos. Porto Alegre: Globo Universidade, 2012. p. 403-446.

OROZCO, G.; FRANCO, D. México: la investigación de la recepción y sus audiencias: hallazgos recientes y perspectivas. In: JACKS, N. (Ed.). Estado del arte de los estudios de recepción de audiencias en América Latina. Quito: Ciespal, 2011. p. 227-266.

OROZCO, G.; MILLER, T. Television in Latin America is "everywhere": not dead, not dying, but converging and thriving. Media and Communication, Lisboa, v. 4, n. 3, p. 99-108, 2016. DOI: http://dx.doi.org/10.17645/mac.v4i3.592

PAZ, O. El laberinto de la soledad. Cidade do México: Fondo de Cultura Económica, 1950.

PISCITELLI, A. Lost: un viaje al centro de la complejidad y la indeterminación, que no está en ninguna parte. In: PISCITELLI, A.; SCOLARI, C.; MAGUREGUI, C. (Eds.). Lostología. Buenos Aires: Cinema, 2010. p. 17-32. PRESS, A.; WILLIAMS, B. The new media environment: an introduction. Oxford: Wiley-Blackwell, 2010.

QUALCOMM advierte el rezago de América Latina en conectividad. Mediatelecom, [S.1.], 2015. Disponível em: <https://bit.ly/1qg6IwM >. Acesso em: 23 nov. 2018.

REPOLL, J. La ilusión de la participación: volver a las mediaciones: del otro lado a muchos lados. In: OROZCO, G. (Coord.). TVmorfosis: convergencia y escenarios para una televisión interactiva. Cidade do México: Tintable, 2014. v. 3. p. 37-53. (Colección Tendencias).

ROJAS, E. F.; POVEDA, L. Informe del estado de la banda ancha en América Latina y el Caribe 2015. Santiago: Comisión Económica para América Latina y el Caribe, 2015. Disponível em: <https://bit.ly/2DWfRMH $>$. Acesso em: 23 nov. 2018.

SCOLARI, C. A. Entrevista a Mario Carlón. Digitalismo, [S.l.], 2013. Disponível em: <https://bit.ly/2DIZ5zk>. Acesso em: 23 nov. 2018.

. Los monstruos de la televisión: discursos esquizofrénicos sobre un medio en transición. In: OROZCO, G. (Coord.). TVmorfosis: la creatividad en la era digital. Cidade do México: Tintable, 2016. v. 5. (Colección Tendencias).

SIMON, H. A. Rational decision-making in business organizations. The American Economic Review, Nashville, v. 69, n. 4, p. 493-513, 1979. Disponível em: $<$ https://bit.ly/2C1OI8T >. Acesso em: 23 nov. 2018. 
SINCLAIR, J.; STRAUBHAAR, J. Latin American television industries. Londres: Palgrave Macmillan, 2013.

SLADE, C.; BECKENHAM, A. Introduction: telenovelas and soap operas: negotiating reality. Television \& New Media, Thousand Oaks, v. 6, n. 4, p. 337-341, 2005. DOI: https://doi.org/10.1177/1527476405279860

SMITH, P. J. Mexican screen fiction: between cinema and television. Cambridge: Polity Press, 2014.

VASSALLO, M. I.; OROZCO, G. Síntese comparativa dos países Obitel em 2013. In: VASSALLO, M. I.; OROZCO, G. (Eds.). Estratégias de produção transmídia na ficção televisiva. Porto Alegre: Globo Universidade, 2014. p. 23-86. VERÓN, E. El fin de la historia de un mueble. In: CARLÓN, M.; SCOLARI, C. (Eds.). El fin de los medios masivos: el comienzo de un debate. Buenos Aires: La Crujía, 2009. p. 20-32.

WENNER, L. A. In search of the sports bar: masculinity, alcohol, sports, and the mediation of public space. In: RAIL, G. (Ed.). Sport and postmodern times. Albany: State University of New York Press, 1998. p. 302-332.

WILLIAMS, R. The politics of modernism: against the new conformists. Londres: Verso, 1989.

Artigo recebido em 7 de novembro de 2018 e aprovado em 21 de novembro de 2018. 